\title{
Incentives, Supervision, and Sharecropper Productivity
}

\author{
Hanan G. Jacoby* Ghazala Mansuri*
}

\begin{abstract}
Although sharecropping has long fascinated economists, the determinants of this contractual form are still poorly understood and the debate over the extent of moral hazard is far from settled. We address both issues by emphasizing the role of landlord supervision. When tenant effort is observable, but at a cost to the landlord, otherwise identical share-tenants can receive different levels of supervision and have different productivity. Unique data on monitoring frequency collected from sharetenants in rural Pakistan confirm that, controlling for selection, "supervised" tenants are significantly more productive than "unsupervised" ones. Also, landlords' decisions regarding the intensity of supervision and the type of incentive contract to offer depend importantly on the cost of supervising tenants.
\end{abstract}

World Bank Policy Research Working Paper 4125, February 2007

The Policy Research Working Paper Series disseminates the findings of work in progress to encourage the exchange of ideas about development issues. An objective of the series is to get the findings out quickly, even if the presentations are less than fully polished. The papers carry the names of the authors and should be cited accordingly. The findings, interpretations, and conclusions expressed in this paper are entirely those of the authors. They do not necessarily represent the view of the World Bank, its Executive Directors, or the countries they represent. Policy Research Working Papers are available online at http://econ.worldbank.org.

*Development Research Group, World Bank. Contact Information: Jacoby: email: hjacoby@worldbank.org; Mansuri: email: gmansuri@worldbank.org. 


\section{Introduction}

Sharecropping, among the archetypical incentive problems, has fascinated economists since Adam Smith (see, e.g., Laffont and Martimort, 2001). Despite the continued high prevalence of sharecropping in much of the developing world and a vast theoretical literature seeking to explain it, there have only been scattered attempts to link observed contractual forms in agriculture to specific models of the principal-agent relationship (recently, see Ackerberg and Botticini, 2002; Laffont and Matoussi, 1995; Pandey, 2004).

Most empirical attention has instead focused on the sharecropper-productivity debate; the question of whether tenant effort is indeed prohibitively costly to monitor, thereby leading to moral hazard (cf., Stiglitz, 1974), or whether underprovision of tenant effort is obviated by landlord supervision (as argued by, e.g., Johnson, 1950). While Shaban's (1987) landmark study appeared to vindicate the moral hazard view, evidence for the 'superiority' of owner-cultivation or fixed rental over sharecropping is, on the whole, inconclusive (Otsuka, et al., 1992; Binswanger, et al., 1995). ${ }^{1}$

In this paper, we argue that heterogeneity in supervision costs has important implications for both of these strands of the empirical literature on land tenancy. To show this, we develop a simple model in which tenant effort is observable and enforceable, but at a cost to the landlord. Tenants vary in their ex-ante wealth, landlords in their cost of supervision, and equilibrium in the tenancy market is achieved through a process of matching along these two dimensions. The model yields two insights: First, otherwise identical share-tenants can receive different levels of supervision and, consequently, have different productivities. Second, a landlord's decisions regarding the intensity of supervision and the type of incentive contract to offer are driven (in a fairly restricted way) by his cost of supervision.

Our empirical work, which uses a large and detailed micro-level data set from rural Pakistan, begins by estimating the average yield differential between sharecropped and owner-cultivated plots cultivated by the same household. We are able to state with high confidence that this differential is small, a conclusion supported by evidence on family labor allocation. Next, using unique information on monitoring frequency collected directly from tenants, we demonstrate that yields on plots cultivated by 'unsupervised' tenants

\footnotetext{
${ }^{1}$ In Laffont and Mattousi's (1995) study of tenancy in a Tunisian village, for example, sharecropper productivity (evaluated at mean tenure duration) is higher than that of owner/renters. On the other hand, recent evidence from a tenancy reform in West Bengal (Banerjee, et al., 2002) shows that a modest reallocation of property rights in favor of share-tenants, falling far short of outright ownership, led to a dramatic yield increase, much greater than any found in farm-household level data.
} 
are significantly lower than yields on plots cultivated by 'supervised' tenants. There are simply not enough of the former type to generate large overall productivity differentials between sharecropped and owner-cultivated plots. Thus, accounting for variation in landlord supervision can help resolve the sharecropper-productivity debate.

The final step in our analysis is to build and estimate an econometric model of contractual choice, tightly linked to the theory, that takes into account both heterogeneity in landlord supervision costs and in tenant wealth. ${ }^{2}$ Consistent with the predictions of our theoretical model, we find that contracts involving high supervision combined with lowpowered incentives are preferred by landlords residing in close proximity to their leased plots-i.e., by those with low supervision costs. This finding complements recent work showing that the nature of the share-contract is, in certain contexts, shaped by risk-sharing considerations (Pandey, 2004). Our contribution is to highlight the role of supervision costs in determining the form of share-tenancy.

The results also have important practical implications. To the extent that sharecropping exerts a serious drag on agricultural productivity, tenancy or land reform may be a rare example of 'win-win' policy. Redistributing property rights over land from wealthy landlords to poor tenants, in other words, could improve both equity and efficiency. Our analysis, however, provides a rather sobering assessment of the potential productivity gains from such policies in a setting where share-tenancy, though widespread, has been hitherto unregulated.

The remainder of the paper is organized as follows. Section 2 describes the baseline analysis of productivity differentials between sharecropped and owner-cultivated plots, as well as the data and context of our study. Section 3 presents the tenancy model with landlord supervision. The implications of the model for productivity differentials are explored in section 4, and for contractual choice in section 5. Section 6 summarizes the findings.

\footnotetext{
${ }^{2}$ As discussed later, the econometric model is also attentive to landlord-tenant matching along these two dimensions (see Ackerberg and Botticini, 2002, for a more general discussion of the empirical issues involved).
} 


\section{Is Sharecropping Less Productive?}

\subsection{Testing for moral hazard}

As a backdrop for our empirical analysis, we make a few standard theoretical assumptions that will later be incorporated into the tenancy model of section 3. Consider a constant returns to scale technology (plot size normalized to one), in which yield $y$ is produced according to $y=f(e, x)+\varepsilon$, where $e$ is tenant effort, $x$ is a purchased input, and $\varepsilon$ is a random output shock. Net productivity is $\pi=y-p x$, where $p$ is the normalized input price. The tenant's disutility of total effort is given by the convex function $v(e)$.

Sharecropping contracts specify an output share $\beta \in(0,1)$ and possibly also a fixed component $\alpha$, which may be negative. We assume that the cost of the purchased input is shared between landlord and tenant at the same rate as is output; in the model we consider later this assumption turns out to be innocuous. Suppose further that tenant effort is noncontractible.

A risk neutral tenant chooses $\left(e_{s}, x_{s}\right)$ to maximize $\beta \pi(e, x)-v(e)-\alpha$, giving firstorder conditions $\beta f_{e}=v /$ and $f_{x}=p .^{3} \quad$ Since any tenancy contract must be incentivecompatible, moral hazard delivers the unambiguous prediction $\frac{d e_{s}}{d \beta}>0$. The marginal effect of share-tenancy on yields is then

$$
\frac{d y}{d \beta}=f_{e} \frac{d e_{s}}{d \beta}+f_{x} \frac{d x_{s}}{d \beta}
$$

which, in general, is ambiguous. A sufficient condition for $\frac{d y}{d \beta}>0$, which we henceforth assume to hold, is

Assumption A.1 $f_{x e}>f_{e} f_{x x} / f_{x}$.

Tests for moral hazard based on yield data, therefore, have power only to the extent that tenant effort does not have very close purchased substitutes. ${ }^{4}$ If $f_{x e}$ is indeed large and negative, then yield differentials between sharecropped and owner-cultivated plots may be negligible even with moral hazard. However, the only input that could conceivably

\footnotetext{
${ }^{3}$ Given the additivity of the shock, precisely the same first-order conditions would hold for a risk-averse tenant. Since we later model share-tenancy as arising from financial constraints, tenant risk aversion is an unnecessary complication.

${ }^{4}$ Since $\frac{d \pi_{s}}{d \beta}=f_{e} \frac{d e_{s}}{d \beta}$ is unambiguously positive, it might seem preferable to perform the test using net rather than gross productivity. In practice, however, there are several purchased inputs, each measured with considerable noise, so that net productivity tends to be less precisely measured than gross productivity.
} 
substitute strongly for tenant effort is hired labor and, if such substitutability were high in all tasks (not just for harvesting; see subsection 2.6), there would be little demand for share-tenants. Landowners could simply self-cultivate using wage labor.

\subsection{Data}

Our empirical analysis draws upon agricultural production data collected in two separate household surveys from rural Pakistan. The first is round 14 of the IFPRI panel survey, fielded in 1993 in four districts and 52 villages. The second is the nationally representative Pakistan Rural Household Survey (PRHS) of 2001, which collected data from about 2,800 households sampled across 17 districts and 150 villages. All of the households in IFPRI-93 were purposively included in PRHS-01. Overall, about $60 \%$ of the households surveyed in 2001 were farm households and, as in 1993, a considerable fraction of these operated multiple plots. Because much of the plot-level agricultural production and tenancy data are comparable across the two surveys, part of the empirical work uses both data sets together. Our analysis of landlord supervision, however, relies solely on the 2001 survey, since the relevant questions were not asked in 1993.

\subsection{Context}

As a consequence of Pakistan's extreme land ownership inequality, the fraction of tenanted land is high (more than a third), and about two-thirds of this land is under sharecropping. Despite numerous tenancy laws on the books (regarding eviction and the sharing of output and costs), contracts are de facto unconstrained, as enforcement is practically nonexistent.

Sharecropping is the predominant form of tenancy in Sindh province, where the land ownership distribution is particularly skewed. According to reports by surveyed tenants, the median landlord owns 28 acres, whereas nearly $80 \%$ of the share-tenants are landless farmers. Large landlords in this region often employ labor supervisors (kamdars) to manage their many tenants. In the Punjab, the second of the major provinces of Pakistan, tenancies are split more evenly between share and fixed rent contracts. Landlords in Punjab are also typically much smaller than in Sindh, with a median holdings of only 7 acres, and are more likely to be resident in the same village as their tenants.

Although nearly three-quarters of share-tenants in our data report a 50-50 output sharing rule, this probably overstates the degree of uniformity in these contracts. For example, it is common for tenants to borrow from their landlords, often by taking an 
advance for their share of the input costs, which is typically repaid at harvest time. Output and cost shares alone thus do not fully characterize the terms of the share-contract.

\subsection{Empirical Strategy}

Our regression model for yields realized by cultivator $c$ on plot $i$ is

$$
y_{c i}=\gamma s_{c i}+\omega / x_{c i}+\nu_{c}+\eta_{c i}
$$

where $s_{c i}$ is an indicator of whether the plot is sharecropped and $x_{c i}$ is a vector of exogenous plot characteristics. Thus, $\gamma$ estimates the average yield differential between sharecropped and owner-cultivated (or rented) plots. The error component $\nu_{c}$ captures unobserved factors common to a given cultivator that determine productivity; e.g., access to credit, farming knowledge, average land quality, and ownership of non-marketed assets more generally. The error component $\eta_{c i}$ reflects plot-specific unobservables, such as soil fertility, that are not contained in $x_{c i}$.

Since, in general, the decision to enter into a sharecropping contract depends upon the cultivator's unobserved productivity, $E\left[\nu_{c} \mid s_{c i}=1\right] \neq 0$ and OLS estimates of $\gamma$ are subject to selection bias. All of the major theories of share-tenancy proposed thus far in the literature imply that $E\left[\nu_{c} \mid s_{c i}=1\right]<0$, i.e., that sharecroppers have lower unobserved productivity than owner-cultivators or fixed renters. ${ }^{5}$ This means that selection bias will, if anything, lead to an overstatement of the disincentive effects of share-tenancy. Our strategy for correcting this selectivity bias is essentially the same as that of Shaban (1987) and Bell (1977). In particular, we use household fixed effects to purge $\nu_{c}$. This procedure requires a sufficient number of owner-cum-sharecropper (OCS) households, owner-cultivators (or renters) that also cultivate at least one sharecropped plot.

Note, finally, that our household fixed effects estimator (as well as the one used by Shaban) is not robust to correlation between $s_{c i}$ and $\eta_{c i}$, as would arise, most plausibly, when there is adverse selection in the leasing market. Under adverse selection, sharecropped

\footnotetext{
${ }^{5}$ Models with limited liability (e.g., Shetty, 1998; Basu, 1992; Mookherjee, 1997; Laffont and Mattoussi, 1995) imply that wealthier cultivators are less likely to be share-tenants, but wealthier cultivators also tend to have more capital and other unobserved inputs. If (following Stiglitz, 1974) share-tenants are more risk averse, then they are also likely to be less productive than owner-cultivators because, firstly, risk aversion is negatively related to wealth and, secondly, because greater risk aversion militates agains the use of riskier but more productive techniques. Under double-sided moral hazard (Eswaran and Kotwal, 1985), both tenant and landlord supply a noncontractible input. In the landlord's case, this can be farming know-how, which the tenant is assumed to lack. Likewise, in Hallagan's (1978) screening model, less able cultivators endogenously select into sharecropping.
} 
land tends to be of lower quality than owner-cultivated land; i.e., $E\left[\eta_{c i} \mid s_{c i}=1\right]<0 .{ }^{6}$ Thus, just as in the previous paragraph, ignoring this form of selection bias when it is present would lead us to understate the productivity of share-tenancy vis à vis ownercultivation. Importantly, this means that a failure to find a negative $\gamma$ using a household fixed effects estimator cannot be due to adverse selection, since adverse selection can only make $\gamma$ appear more negative. In other words, our estimate of the disincentive effects of share-tenancy is (at worst) an upper bound.

\subsection{Productivity results}

We focus on production of the five major crops: wheat, rice, cotton, sugarcane, and maize. Wheat is the principal crop cultivated in the rabi season (November-May), whereas rice, cotton, and maize are grown in the kharif season (May-November). Sugarcane is grown year-round, but is usually planted in kharif. Land devoted to fodder and a number of minor crops is excluded from consideration, as these outputs are difficult to measure accurately. In the IFPRI-93 sample, the five major crops account for $66 \%$ of cultivated area (71\% of sharecropped area); the corresponding figure for the nationally representative PRHS-01 sample is $80 \%$ (83\%). Yield is defined as the value of output from these five crops evaluated at median prices for that year divided by area planted to these crops. ${ }^{7}$ For ease of presentation of the yield results in Table 2, the dependent variable is scaled (see Appendix) so that $\gamma$ is interpretable as a percentage deviation relative to ownercultivators/fixed renters.

Recall that the IFPRI-93 and PRHS-01 samples partly overlap to form a panel. For our purposes, this overlap is not large given the criterion that households cultivate at least one of the five major crops in both survey rounds. In our final sample, $16 \%$ of the households appear both in 1993 and 2001, contributing 29\% of the plots. With such panel data, there are two ways to implement the household fixed effects procedure described in section 2.4: either group plot-level observations by household irrespective of survey year (household basis), or group plots of a given household separately by survey year (household-year basis). The latter specification is less restrictive in that it allows

\footnotetext{
${ }^{6}$ While it is true that plots taken on fixed rent are also subject to adverse selection, only $5 \%$ of our estimation sample consists of renter-cum-sharecroppers. So, for the most part, we are comparing sharecropped to owner-cultivated plots.

${ }^{7} \mathrm{~A}$ small number of observations (27 in all) were dropped because of probable coding errors that generated excessive yields. Including these observations has a negligible impact on the results, but does raise the standard errors on the coefficient of interest by about $6 \%$.
} 
for nonstationarity in household endowments (i.e., in $\nu_{c}$ ). ${ }^{8}$ Since, in using the household basis, it is likely that the same plot will appear twice in a given household group, we correct the standard errors in this case for clustering on household. ${ }^{9}$ Table 1 breaks down the number of plots available, by survey year. With respect to the household-year basis, the yield sample consists of 1,718 plots belonging to households with multiple plots. Of these, 403 belong to owner-cum-sharecropper households, ${ }^{10}$ and the rest to pure sharecroppers or owner-cultivator households. Including this latter group of households increases the precision of the estimates when we control for plot characteristics. Using the household basis boosts the multiple-plot household sample to 1,993 and the number of plots among these cultivated by owner-cum-sharecroppers to 771 .

Our regressions control for the most important plot characteristics: area, value, location, irrigation, and soil type. We also control for the crop composition on a plot - i.e., the fraction of area planted to each of the five major crops - and allow these composition effects to vary by survey year so as to capture any changes in relative crop prices. Table A.1 in the Appendix describes these variables.

While, in theory, crop choice may be specified in the tenancy contract, and hence endogenous, in Pakistan, share-tenants generally have autonomy over crop choice and grow basically the same mix of crops as owner-cultivators. Indeed, for all five of the major crops in our yield measure, there is no significant difference in the proportion of area cultivated between sharecropped and other plots, once we control for tehsil (there are 23 tehsils or subdistricts in our sample).

The first three specifications in Table 2 use the less restrictive household-year basis for the fixed effects. Without any covariates, we find that yields are about $3 \%$ lower on sharecropped plots. Sequentially adding controls for plot characteristics and crop composition in columns (2) and (3), respectively, lowers this estimate of $\gamma$ only slightly, along with the standard error. For the sake of brevity, we do not report the individual coefficients on the plot characteristics and crop composition variables. However, they are highly jointly significant in all specifications as indicated in Table 2. Results are virtually identical when we use the household basis for the fixed effects and there is no evident gain

\footnotetext{
${ }^{8}$ For example, in the eight years between the two rounds of the survey, a household's farm assets or financial position may have changed.

${ }^{9}$ Because only households were followed and not individual plots, one cannot say for sure how many of the same plots were captured in PRHS-01. However, it is likely that most of the owner-cultivated plots and many of the leased plots belonging to panel households are in fact the same across survey rounds.

${ }^{10}$ Owner-cum-sharecropper households are over-represented in the IFPRI survey by geographical accident; these households tend to be concentrated in central Punjab.
} 
in precision from doing so. All in all, then, there is no significant productivity difference between sharecropped and owner-cultivated plots.

How informative is our failure to reject the null hypothesis of equal productivity? Andrews' (1989) inverse power (IP) function allows us to quantify the set of alternatives against which our test has power. Based on yield specification (3) in Table 2, we would be equally likely as not to reject the null if the true yield differential were $6.5 \%$; this figure demarcates the region of low power. On the other hand, if the true yield differential were $13 \%$, we would be $95 \%$ certain of rejecting the null. Thus, our test has high power against yield differentials exceeding $13 \%$.

Although $13 \%$ is a respectable number, we may do better with the more restrictive village fixed effects specification. This estimator, the results of which are reported in column (5) of Table 2, is not robust to the selection problem outlined above, but may be more efficient than household fixed effects, in part because it exploits a much larger 2,807 plot sample (see Table 1). In addition to village fixed effects, we allow for household random effects to deal with the correlation across plots within multi-plot households. As it happens, the village fixed effects estimates of $\gamma$ are less negative than their household fixed effects counterparts, which would be contrary to expectations except for the fact that this difference is not remotely significant; the two estimates are within a standard error of each other. Selection bias, therefore, does not appear to be a serious problem. ${ }^{11}$ With an almost $40 \%$ lower standard error, however, the village fixed effects estimator of $\gamma$ is much more precise than the ones based on household fixed effects. As a consequence, we can now be $95 \%$ certain that the true yield differential is no greater than $8 \%$.

\subsection{Labor results}

A more direct test for moral hazard is to compare the cultivator's family labor input on sharecropped versus owned plots. IFPRI-93 (but not PRHS-01) provides information on plot-level labor inputs. These data are collected for each type of worker (adult male and female, and male and female child), but since the vast majority of farm labor is supplied by adult men in this sample, we sum the days of all worker types. Farm labor inputs are also disaggregated by task (plowing/irrigation, sowing, weeding, harvesting, and threshing), which we initially combine. On average, families supply a total of 16 days annually for each acre cultivated.

\footnotetext{
${ }^{11}$ Again using the IP function, we can be $95 \%$ certain that the household fixed effect estimate of the yield differential is within 11 percentage points of the village fixed effect (household random effect) estimate. In other words, we would be very likely to detect moderate selection bias if it existed.
} 
For the family labor input regressions in the lower panels of Table 2, we use essentially the same approach as we did with yields. ${ }^{12}$ Based on the household fixed effects estimates, we find that total family labor per acre is about $6 \%$ lower on sharecropped plots than on owner-cultivated plots, but this difference is not significant. Unlike the case of yields, the estimated magnitude of the labor differential falls considerably after adding the controls. The village fixed effects estimate is somewhat more precise than that based on household fixed effects, but in this case a Hausman test rejects the former specification ( $p$-value $=0.006$ ). Conservatively, then, our test of the null of zero moral hazard has high power against family labor use differentials on the order of $20 \%$.

A more powerful test of moral hazard focuses on those tasks that are difficult to contract. Data from the farm wage employment section of PRHS-01 indicate that harvesting effort is much easier to monitor than effort in land preparation, weeding, and so forth. Two-thirds of all annual paid labor days in agriculture are for harvesting, compared to just $7 \%$ for weeding and $4 \%$ for tilling, and harvesting jobs are much more likely to pay piece rates, which rely on directly observing output or effort. Thus, using a family labor regression that excludes days spent harvesting and threshing (almost half of all family labor devoted to the average plot), the null hypothesis of zero moral hazard should be more likely to be rejected if it is indeed false. These regressions are estimated on exactly the same sample as for total family labor (see Table 1), and the results are reported in the bottom panel of Table 2. Surprisingly, the differential between sharecropped and owner-cultivated plots in terms of noncontractible family labor is only $2 \%$ (column (3)). This leads us to suspect that even the $6 \%$ overall family labor differential may overstate the extent of moral hazard.

\subsection{Discussion}

To sum up, we find no significant yield shortfall on share-tenanted land vis à vis owner-cultivated/rented land. Using similar procedures and data, Shaban (1987) obtains a significant $16 \%$ yield differential in six south Indian villages. We can rule out an effect of such magnitude with virtual certainty in neighboring Pakistan. Shaban also estimates that owner-cum-sharecroppers allocate $21 \%$ less male family labor overall ( $47 \%$ less female labor) to their sharecropped plots than they do to their owned plots (ICRISAT labor data

\footnotetext{
${ }^{12}$ We do, however, take logs of labor hours instead of levels, as the former gives higher within $R^{2} s$ in the fixed effect regressions and thus considerably lower standard errors. The standard errors of the percentage changes are calculated using the approximation formula given by van Garderen and Shah (2002).
} 
are not disaggregated by task). Based on our findings, family labor differentials this large in rural Pakistan are highly improbable.

Otsuka, et al. (1992), faced with similar (though perhaps less conclusive) evidence, echo Johnson (1950) in surmising that supervision and enforcement of share-tenant effort must be broadly effective. Sharecropping, they argue, is adopted as long as monitoring costs are low enough to make it worthwhile relative to fixed rental. They go on to suggest that "significant inefficiency of share-tenancy is expected to arise only when the scope of contract choice is institutionally restricted" (p. 2007). Thus, rather than evidence of the general inefficiency of sharecropping, they view Shaban's (1987) findings as an aberration arising from India's legal environment. When land-to-the-tiller legislation effectively penalized long-term tenancy contracts, many landlords with high supervision costs switched from fixed rent to share contracts, since sharecroppers were easier to disguise as permanent farm laborers.

The proposition that sharecropper productivity increases with the degree of supervision has, however, rarely been subjected to empirical testing. ${ }^{13}$ The rest of this paper formalizes and carries out such a test.

\section{A tenancy model with supervision}

\subsection{Costless supervision}

When tenant effort can be monitored and enforced at zero cost, effort levels are firstbest. Using our earlier notation, the landlord selects a fixed payment $\alpha$, an output share $\beta$, tenant effort $e$, and $x$ to

$$
\begin{aligned}
& \operatorname{Max}(1-\beta) \pi(e, x)+\alpha \quad \text { s.t. } \\
& \beta \pi(e, x)-v(e)-\alpha \geq 0
\end{aligned}
$$

where the second line is the tenant's participation constraint $(\mathrm{PC})$ with outside utility normalized to zero. ${ }^{14}$ The optimal $\left(e^{*}, x^{*}\right)$ sets $f_{e}=v_{e}$ and $f_{x}=p$. Contract type is

\footnotetext{
${ }^{13} \mathrm{Ai}$ et al. (1997) is the only other attempt that we are aware of. Using a different modelling approach and plot-level data from a single Tunisian village, they find, paradoxically, that crop yield is a decreasing function of the frequency of landlord visits to the tenant.

${ }^{14}$ The fixed payment $\alpha$ may be negative, in which case the contract has a credit element to the extent that such payments are made up front. This 'loan' is repaid at harvest time through the output share $\beta$. Formally, the model abstracts from the timing of payments.
} 
indeterminate, as the landlord can choose any combination of $\alpha$ and $\beta$ that satisfy the tenant's PC.

Next, we introduce a financial constraint (FC) as in Laffont and Matoussi (1995), which specifies that the tenant cannot be made to pay more up front than he has in wealth $w$. The tenant's up-front contributions to rent $(\alpha)$ and input costs $(\beta p x)$ are thus constrained by $\alpha+\beta p x \leq w$. Since the landlord can still choose tenant effort costlessly, the addition of the FC has no efficiency implications; effort is still first-best. However, tenants with wealth below a certain threshold will be offered crop-sharing contracts, as they cannot afford the up-front payments that a fixed rent contract $(\beta=1)$ entails. ${ }^{15}$

\subsection{Costly supervision}

When tenant effort is prohibitively costly to observe, the presence of a binding FC does have efficiency implications. While tenants with sufficient wealth $(w \geq \underline{w})$ get fixed rent $(F R)$ contracts and provide first best effort $e^{*}$, poorer tenants $(w<\underline{w})$ get share $(S)$ contracts and provide less effort, $e_{s}<e^{*}$. Figure 1 shows the landlord's return falling with tenant wealth, as the amount that can be extracted up-front declines. Below a certain wealth level, however, the landlord may prefer to relinquish some rents to the tenant to induce effort. We assume that this case is not empirically relevant, perhaps because, as Laffont and Matoussi argue, the landlord would prefer a wage contract over share-tenancy for such a low-wealth agent. Given that the PC is binding, the landlord's return for a tenant with $w<\underline{w}$ is $r_{s}=\pi\left(e_{s}, x_{s}\right)-v\left(e_{s}\right)$.

Suppose now that, as an alternative to leaving his tenant unsupervised, the landlord can monitor effort, but at a cost. ${ }^{16}$ Let $c(e)$ represent the cost of implementing a given level of effort, where $c_{e}>0$ and $c_{e e} \geq 0$. The landlord's problem is now

$$
\begin{aligned}
& \operatorname{Max}(1-\beta) \pi(e, x)+\alpha-c(e) \quad \text { s.t. } \\
& \beta \pi(e, x)-v(e)-\alpha \geq 0 \\
& \alpha+\beta p x-w \leq 0
\end{aligned}
$$

\footnotetext{
${ }^{15}$ Allowing the landlord to set the tenant's share of the input cost independently from the output share has no effect on this or on subsequent analyses. When the financial constraint is binding, the input share drops out of both the landlord's objective function and the tenant's participation constraint; only the total amount that the tenant pays up front is relevant to the contracting parties.

${ }^{16}$ Demougin and Fluet (2001) and Allgulin and Ellingsen (2002) examine supervision in a principal-agent framework with ex-post limited liability and a probablistic monitoring technology, but these models are not well-suited to our application.
} 
The interesting case involves share-tenancy (i.e., FC binding), as monitoring is redundant in a fixed rent contract. Under the monitored share $(M S)$ contract, effort is chosen according to $f_{e}=v_{e}+c_{e}$. Since the cost to the landlord of inducing tenant effort is always higher than the tenant's marginal disutility, optimal effort is $e_{m}<e^{*}$.

In the $M S$ contract, the tenant's PC is binding at all wealth levels and the landlord's return, $r_{m}=\pi\left(e_{m}, x_{m}\right)-v\left(e_{m}\right)-c\left(e_{m}\right)$, is independent of tenant wealth. Let $\theta$ index landlords such that $d c(e ; \theta) / d \theta>0$. Figure 1 shows two landlords, $H$ and $L$, with high and low supervision costs, respectively, such that $\theta_{L}<\theta_{H}$ and hence $r_{m}^{L}>r_{m}^{H}$. For landlord $L$, it is optimal to offer the $M S$ contract to any tenant with wealth below $\underline{w}_{L}$ and to offer the $S$ contract to any tenant with $w \in\left[\underline{w}_{L}, \underline{w}\right)$. The same applies to landlord $H$ at wealth threshold $\underline{w}_{H}<\underline{w}_{L}$. Given $\partial r_{s} / \partial \theta=0$ and $\partial r_{m} / \partial \theta<0$, it follows that

Proposition 1 An increase in $\theta$ lowers the wealth threshold below which the landlord supervises his share-tenant, but has no effect on the wealth threshold above which he offers a fixed rent contract.

We are now ready to address our main question: Does landlord supervision increase the productivity of a share-tenancy, holding tenant wealth constant? The way to think about this for, say, landlord $L$ is to fix tenant wealth at some $w$ that is just epsilon above $w_{L}$, so that he chooses contract $S$. Now lower $\theta$ (raise $r_{m}$ ) by some tiny amount delta so that the landlord is just willing to switch the tenant from the $S$ to the $M S$ contract. The question is whether tenant effort is higher after the switch. Since $M S$ is now chosen, we have that $r_{m}^{L}>r_{s}^{L} \Longrightarrow\left[\pi\left(e_{m}^{L}, x_{m}^{L}\right)-v\left(e_{m}^{L}\right)\right]-\left[\pi\left(e_{s}^{L}, x_{s}^{L}\right)-v\left(e_{s}^{L}\right)\right]>c\left(e_{m}^{L}\right)>0$. Further, since the function $\pi-v$ attains a maximum at $\left(e^{*}, x^{*}\right)$ and both $e_{m}^{L}$ and $e_{s}^{L}$ are less than $e^{*}, \pi-v$ must be increasing over this range of effort. It follows, therefore, that $e_{m}^{L}>e_{s}^{L}$. The landlord must get more effort out of the tenant in the $M S$ contract in order to justify his added supervision cost. Thus, we have

Proposition 2 Under Assumption A.1 and for a given w, yield is higher in a sharecontract with supervision than in one without supervision.

\subsection{Matching equilibrium}

It is easily seen that landlords with high supervision costs prefer high wealth tenants at least as much as landlords with low supervision costs. Since the tenant's PC is always binding, the total surplus from a landlord-tenant match is given by $r^{i}=\max \left\{r_{m}^{i}, r_{s}^{i}\right\}$, 
$i=L, H$. With two types of landlords (high/low supervision costs) and two types of tenants (high/low wealth), social surplus is $\psi\left(w, w^{\prime}\right)=r^{L}(w)+r^{H}\left(w^{\prime}\right)$ for any pair of tenants $\left(w, w^{\prime}\right)$. One can verify using Figure 1 that $\psi\left(w, w^{\prime}\right) \geq \psi\left(w^{\prime}, w\right)$ for any tenant pair such that $w<w^{\prime}$. In the case where $w^{\prime}<\underline{w}_{L}$, for instance, landlord $L$ 's relatively high payoff from the $M S$ contract is invariant to tenant wealth, whereas landlord $H$ 's payoff is increasing in $w$. Higher surplus is thus achieved when the richer tenant works $H$ 's land on an $S$ contract instead of $L$ 's land on an $M S$ contract.

We can now sketch out a simple model of landlord-tenant matching with search frictions. Prior to contracting, potential tenants randomly drawn from the wealth distribution arrive sequentially before landlords who can either accept or reject them. If rejected, the tenant reenters the candidate pool. ${ }^{17}$ Given that searching for tenants is costly, landlords will adopt a "reservation wealth" strategy; that is, they will make a hire once they find a tenant whose wealth exceeds a given threshold. Since, by the above argument, landlords with higher supervision costs must have higher reservation wealth, we obtain

Proposition 3 In equilibrium, tenant wealth and landlord supervision costs are positively, but not perfectly, correlated.

\section{Are Supervised Sharecroppers More Productive?}

\subsection{Quantifying landlord supervision}

PRHS-01 asks each share-tenant "during [kharif/rabi season] how many times did the landlord meet with you to discuss or supervise your activities on this plot." In case the landlord employed labor overseers, or kamdars, the same question was asked about meetings between the tenant and these individuals as well. Very few share-tenants (less than $4 \%$ ) report never having had supervisory meetings with their landlord or with a kamdar during the year (meetings with kamdars occurred in about a quarter of sharetenancies). On one-half of all sharecropped plots, tenants report having had more than 30 meetings per year with their landlord/kamdar, and, on half of these plots, tenants claim to have had at least 90 meetings. While many of these conversations may have occurred during non-crucial periods or were not otherwise intended to elicit or enforce effort on the part of the tenant, it is clear that share-tenants in Pakistan are not being left to their own

\footnotetext{
${ }^{17}$ It is reasonable to assume in our setting that tenants also face search costs, thus allowing landlords to make "take-it-or-leave-it" offers at the time of contracting.
} 
devices (Nabi, 1986, provides similar evidence in a smaller scale survey). ${ }^{18}$

We certainly do not want to treat supervision intensity as linear in the number of meetings, since there must be diminishing returns beyond a point, and possibly increasing returns at very low numbers of meetings as well. The simplest empirical approach, and the one we adopt here, is to assume a threshold number of annual meetings above which a tenant can be considered 'supervised'. But, what should this threshold be? This is a question on which we will let the data speak.

To this end, we estimate a version of Hansen's (1999) threshold regression model for panel data. Let $m_{c i}$ be the number of meetings that cultivator $c$ on plot $i$ had with his landlord (defined only for sharecropped plots). Our modified yield regression is then

$$
y_{c i}=\gamma s_{c i}+\delta s_{c i} I\left(m_{c i}>k\right)+\omega \prime x_{c i}+\nu_{c}+\eta_{c i}
$$

where $I(\cdot)$ is the indicator function and $k$ is the threshold, which is treated as a parameter to be estimated. For ease of interpretation, we demean the supervision indicator using $E\left[I\left(m_{c i}>k\right) \mid s_{c i}=1\right]$, so that $\gamma$ continues to estimate the mean difference in yields between sharecropped and owner-cultivated/rented plots.

Selection bias could be a problem here as well. Or, to put it another way, supervision could be endogenous. Landlords may choose which tenants to supervise based on ability or other unobserved productive attributes. If, for example, low productivity cultivators are monitored more intensively, then we would find a spurious negative relationship between yields and supervision. Estimation of equation 4 with household fixed effects, as in section 2 , can correct for this problem to the extent that the cultivator-specific unobservable is constant across tenanted and owned plots. But, this estimator it not robust to selection on tenant type. In particular, landlords may decide which tenants to supervise based on tenant characteristics that do not influence productivity on the tenant's own land. This would essentially give rise to an additional error component of the form $s_{c i} \mu_{c}$. To purge this component, we use a sample of tenant households with multiple sharecropped plots $\left(s_{c i}=1 \forall i\right)$ to estimate the following regression by household fixed effects:

$$
y_{c i}=\delta I\left(m_{c i}>k\right)+\theta \prime x_{c i}+\mu_{c}+\nu_{c}+\eta_{c i},
$$

where $\mu_{c}+\nu_{c}$ is the fixed effect (and $\gamma$ is absorbed in the constant term).

\footnotetext{
${ }^{18}$ Supervision is most intense in Sindh province (with a median of 48 annual meetings versus 8 for the remaining three provinces taken together), where landlords typically have larger holdings and are more likely to employ kamdars.
} 


\subsection{Supervision and Productivity}

\subsubsection{Main results}

Our analysis of supervision and yields is based on a sample of 1256 plots cultivated by multi-plot households in PRHS-01 (see Table 1). Replicating specification (3) in Table 2 on this smaller sample, we obtain a yield differential of $-4.2 \%$ (4.8), which is very similar to, but less precise than, our earlier result. To estimate the monitoring threshold $k$, we search over values of $m_{c i}$ within a reasonable range and find the $\widehat{k}$ that minimizes the sum of squared residuals $\left(\sum \widehat{\eta}_{c i}^{2}\right.$ ) from equation 4 (see Hansen, 1999, for details). ${ }^{19}$ Although conventional standard errors on the coefficients in equation 4 , which treat $\widehat{k}$ as the true value of $k$, are asymptotically valid, the test of the null hypothesis $\delta=0$ is non-standard, since $k$ is not identified under the null. We thus adopt the bootstrap $F$-test proposed by Hansen (1999).

Household fixed effects regressions, including plot characteristics and crop composition, are reported in Table 3. For baseline specification (1), the estimation algorithm produces an optimal threshold value of 10 meetings. In other words, the definition of supervision that best fits the data is one in which the tenant meets his landlord at least 11 times per year, or about once each month. Notice that the average yield differential between sharecropped plots and owner-cultivated/rented plots remains about $-4 \%$ after including this supervision variable. Supervised tenants, however, achieve $28 \%$ higher yields than unsupervised ones, and this difference is just about significant using the bootstrap $F$-test $(p$-value $=0.051)$. According to our data-derived definition, about two-thirds of the 351 share-tenanted plots in this sample receive supervision from their landlords and/or the landlord's kamdar. $^{20}$ Viewed in comparison to owner/rented cultivated plots (after a suitable rescaling of the coefficients), plots cultivated by supervised tenants realize $3.0 \%$ (5.6) higher yields, a trivial difference. By contrast, land cultivated by unsupervised tenants is $17.8 \%$ (7.2) less productive than owner/renter cultivated land. This latter figure is remarkably close to the $-16 \%$ yield differential relative to owner-cultivated land found by Shaban (1987) for all share-tenanted plots in his Indian sample.

\footnotetext{
${ }^{19}$ We restrict the search for $k$ between the 10 th and 50th percentiles of $m_{c i}$ among the 351 sharecropped plots in this sample. The 50th percentile is 21 annual meetings, which is already fairly intensive supervision.

${ }^{20}$ Note that this subsample of tenants is somewhat unrepresentative as it excludes sharecroppers of single plots, who are more likely to be from Sindh province and have large landlords. Supervision is considerably higher $(75 \%)$ in the full sample of share-tenants.
} 


\subsubsection{Robustness}

To assess robustness to other potentially confounding factors, we fix the value of $\widehat{k}$ at 10 and add alternative sets of controls. Our first concern is that supervision is picking up characteristics of the tenancy that may have independent effects on yields. Perhaps newer tenants, whose abilities are less familiar to the landlord, are more heavily supervised and are also less productive. Specification (2) in Table 3 thus includes a dummy variable indicating that the share-tenancy has lasted no more than 3 years; it does not attract a significant coefficient. The number of landlord-tenant meetings could also reflect the social relationship between the two, which may have independent productivity effects. Yet, there is no evidence that this is the case, given the insignificant effect of a dummy for whether the landlord and tenant are related (including membership in the same caste/clan). Lastly, wealthier landlords may supervise more and, at the same time, might provide more or better quality inputs to their tenants. In specification (3), we control for the land, tractor, and tubewell ownership of the landlord, which, as before, has a negligible impact on the supervision coefficient. Specification (4) includes both sets of extra control variables together, also with no change in $\widehat{\delta}$.

Another type of concern is that tenants on certain plots - for example, those that are more fertile - receive more supervision and that these plots give systematically different yields. Although we cannot control for unobserved attributes of the plot, we can check whether the estimates change when we do not control for observed attributes. As emphasized by Altonji, et al. (2005), such tests are only as good as the explanatory power of the covariates. In the present case, the removal of all plot-level controls from specification (1) reduces the within household $R^{2}$ substantially, from 0.091 to 0.017 . At the same time, the estimate of $\delta$ becomes 25.4 (11.1), which is practically indistinguishable from its counterpart in Table 3. Thus, to the extent that selection on observables is an accurate guide to selection on unobservables, our estimates are unlikely to suffer from the latter problem.

Our final set of robustness checks allows for the possibility that supervision is correlated with unobserved tenant characteristics. Table 4 presents estimates of equation 5 on the sub-sample of 113 households that cultivate at least two plots on share contracts (264 plots in all). Thus, instead of comparing yields on sharecropped plots (supervised or unsupervised) with yields on owned/rented plots cultivated by the same households, as in Table 3, here we compare yields on supervised sharecropped plots with yields on unsupervised plots cultivated by the same households. In specification (1), we run the 
threshold estimation algorithm with household fixed effects on this new sample to obtain $\widehat{k}=9$, practically the same value as before. In this case, however, the effect of supervision is quite large, raising yields by $73 \%$ versus our earlier $28 \%$, and highly significant, with the bootstrap $F$-test $p$-value coming in at 0.006. Specifications (2)-(4) show, once again, that $\widehat{\delta}$ is robust to the inclusion of the additional controls. In sum, our finding that landlord supervision enhances yield on sharecropped plots does not appear to be driven by tenant-specific unobservables. Indeed, $28 \%$ may well be a lower bound on the impact of supervision on sharecropper productivity.

\section{Supervision Costs and the Form of Tenancy Contract}

\subsection{Econometric Model}

We have argued that differences in the form of tenancy, and, ultimately, in tenant productivity, are driven by variation in costs of supervision. To test this proposition directly, we now turn to an analysis of the landlord's choice among alternative tenancy contracts. Based on the theory in section 3, we build an econometric model of landlord choice across $S, M S$ and $F R$ (fixed rent) contracts from the following equations:

$$
\begin{aligned}
r_{m} & =a \theta+\kappa_{m} \prime x \\
r_{s} & =b w+\kappa_{s} \prime x \\
\underline{w} & =\sigma_{1} \prime x \\
w & =c \theta+\xi
\end{aligned}
$$

The first two equations are linearized versions of the two return functions. The landlord's return on the $M S$ contract depends negatively on his supervision costs $(a<0)$, but is invariant to tenant wealth, whereas the return on the $S$ contract is increasing in tenant wealth $(b>0)$, but invariant to supervision costs. Each return function, as well as the fixed rental wealth threshold $\underline{w}$, are also allowed to depend on plot characteristics $x$ (which includes a constant). Equation $6 \mathrm{~d}$ is the matching function with match error $\xi$ being the sole source of randomness. ${ }^{21}$ Proposition 3 implies that $c>0$.

\footnotetext{
${ }^{21}$ See, e.g., Ackerberg and Botticini (2002). These authors also allow for imperfect observability of principal/agent characteristics by the econometrician. In our case, $\theta$ can be proxied by a variable $z$ such that $\theta=\lambda z+u$, where $u$ is a measurement error and $\operatorname{sign}(\lambda)$ is known a priori. It is easy to see, after substitution into equations $6 \mathrm{a}$ and $6 \mathrm{~d}$, that this generalization merely adds another independent source
} 
Putting these equations together, the landlord's choices are characterized as follows:

$$
\begin{aligned}
M S & \Longleftrightarrow r_{m}>r_{s} \Longleftrightarrow \xi<d_{1} \theta+\sigma_{2} \prime x \\
S & \Longleftrightarrow r_{m} \leq r_{s} \text { and } w<\underline{w} \Longleftrightarrow d_{1} \theta+\sigma_{2} \prime x \leq \xi<d_{2} \theta+\sigma_{1} \prime x \\
F R & \Longleftrightarrow w \geq \underline{w} \Longleftrightarrow d_{2} \theta+\sigma_{1} \prime x \leq \xi
\end{aligned}
$$

where $d_{1}=\left(\frac{a}{b}-c\right), d_{2}=-c$, and $\sigma_{2}=\left(\kappa_{m}-\kappa_{s}\right) / b$. Contract choice probabilities can thus be estimated using an ordered logit model, generalized to allow the slope coefficients to vary with the categorical value of the dependent variable.

There are three testable restrictions: $d_{1}<0, d_{2}<0$, and $d_{1}-d_{2}<0$. Intuitively, higher supervision costs affect contract choice by directly lowering the landlord's return to monitoring a tenant as well as by increasing the attractiveness to him of wealthier tenants, who can be given stronger incentives and concomitantly less supervision. The combination of these two effects, however, operates only at the margin between the $M S$ and $S$ contract, whereas the matching effect alone operates at the margin between the $S$ and FR contract (cf., proposition 1). This fact allows us to identify the ratio of structural determinants of contract choice, i.e., $\frac{a}{b}=d_{1}-d_{2}$, subject to the usual normalization in a discrete choice model.

\subsection{Contract choice results}

PRHS-01 not only asks landlords about each of their tenants and the terms of their contract, but also about the number of supervisory meetings that they or their kamdars had with their tenant. Thus, we can use the threshold number of annual landlord-tenant meetings (10) estimated in section 4 to construct an analogous supervision indicator on the landlord side. Based on this definition, out of 609 leased plots in our landlord sample, 29\% are given on fixed rent, $25 \%$ on 'unsupervised' share-contracts, and $46 \%$ on 'supervised' share-contracts. ${ }^{22}$

of error in the contract choice equations. The reason for the irrelevance of the proxy relationship here is that, contrary to Ackerberg and Botticini, we do not condition on both observed principal and agent characteristics in the contract choice model.

${ }^{22}$ Because Sindh is dominated by very large landowners, with a low sampling probability, our subsample of 432 sharecropped plots on the landlord side is weighted toward NWFP (44\%) and away from Sindh (25\%). By, contrast, $52 \%$ of the 351 sharecropped plots in the Table 3 sample are in Sindh, compared to $25 \%$ in NWFP. The upshot is that the use of kamdars, largely a Sindh phenomenon, is rarely reported in the landlord sample, and the overall intensity of supervision is somewhat lower than on the tenant side. 
To implement the econometric model, we need a variable that shifts the cost of supervision. A natural candidate for $\theta$ is a measure of the accessibility of the plot to the landlord. We use the location of the plot relative to the landlord's village; $14 \%$ of plots are outside the landlord's village of residence. Although we do not have the actual distance between the plot and the landlord's house, in most cases a plot in a different village will not be within walking distance, whereas a plot inside the village will be no more than a kilometer or two away.

Table 5 reports the generalized ordered logit estimates based on 7 . Included in $x$ are the plot characteristics used previously, plus dummies for whether the contract applies to the kharif or rabi seasons only and dummies for the four provinces (Punjab, Sindh, NWFP, and Balochistan). The first two columns under specification (1) report the estimates of the threshold parameters for, respectively, the margin between the $S$ and $M S$ contracts and the margin between the $F R$ and the $S$ contracts. Thus, for example, the coefficient -1.59 in the first column is an estimate of $d_{1}$ (scaled by the error variance) and the coefficient -0.766 in the second column is the corresponding estimate of $d_{2}$. As indicated in the table, we can strongly reject all three null hypotheses, $d_{1}=0, d_{2}=0$, and $d_{1}=d_{2}$ against their respective one-sided alternatives, $d_{1}<0, d_{2}<0$, and $d_{1}-d_{2}<0$.

A possible caveat, however, is that only a select group of landlord's may own plots outside their village. These landlords, in turn, may prefer particular types of contracts for reasons unrelated to supervision costs on the plot. For example, large and wealthy landlords may be more likely to own distant plots and to supervise their share-tenants. To address this problem, specification (2) of the contract choice model controls for landlord characteristics; namely, ownership of land, tractors and tubewells. While these asset variables do significantly affect the choice between $S$ and $M S$ contracts (although not in a consistent direction), their inclusion has little effect on the results of interest. Indeed, our key finding that greater supervision costs lower the returns to tenant monitoring (i.e., $\left.\frac{a}{b}<0\right)$ is even strengthened.

\section{Conclusions}

Recent research suggests that tenancy or land reform may be among the elusive 'winwin' policies. While redistributing land rights to poor peasants clearly has attractive equity implications, Banerjee, et al.'s (2002) findings imply that such redistributions can lead to large efficiency gains as well. This paper delivers a less sanguine conclusion. Our 
evidence shows that gross productivity of land cultivated by sharecroppers differs little from that of land cultivated by owners and fixed renters. At most, this yield differential can be $8 \%$, and our point estimates are less than half this magnitude. In Pakistan, at least, giving higher powered incentives to share-tenants would not have a dramatic impact on agricultural productivity. ${ }^{23}$

The overall efficiency implications, however, are more difficult to assess. Maintaining share-tenant productivity requires fairly heavy landlord supervision. Our evidence shows that yield on land cultivated by sharecroppers who are monitored by their landlords the majority of share-tenants in Pakistan - is at least $28 \%$ higher than yield on land cultivated by unmonitored sharecroppers. Since this supervision is costly to the landlord, either in his own time or in money (for hiring labor overseers), redistributing land rights would generate an efficiency gain by eliminating the need to supervise. Nevertheless, it is improbable that the total resources expended on supervising tenants would come close to matching the gross return on supervision uncovered in this paper, although a definitive answer to this question must await further research.

Putting aside the policy question, this paper has also shown how explicit treatment of landlord supervision and recognition of heterogeneity in productivity differentials can cut through some of the confusion in the existing empirical literature on sharecropping. It is at least empirically plausible that Shaban's (1987) influential finding of a large productivity advantage of owner-cultivation over sharecropping is due to legal constraints on tenancy that effectively created a large number of unsupervised sharecroppers. More broadly, this paper provides evidence on an important element underlying the form of incentive contracts: the principal's cost of supervision. Further work along these lines would greatly enhance our understanding of real-world contracting problems.

\footnotetext{
${ }^{23}$ In Jacoby and Mansuri (2006), we reach similar conclusions regarding land-specific investment. Although such investment is substantially lower on tenanted land, the effect on yields is probably quite small.
} 


\section{References}

[1] Ackerberg, D. and M. Botticini (2002): "Endogenous Matching and the Empirical Determinants of Contract Form," Journal of Political Economy, 110(3):564-90.

[2] Altonji, J., T. Elder and C. Taber (2005): "Selection on Observed and Unobserved Variables: Assessing the Effectiveness of Catholic Schools," Journal of Political Economy, 113(1): 151-83.

[3] Ai, C., J.-L. Arcand, and F. Ethier (1997): "De l'Efficacite Allocative des Contrats Agricoles: Cheung avait-il Raison?" Revue d'economie du developpement, 2: 103-27.

[4] Allgulin, M. and T. Ellingsen (2002): "Monitoring and Pay," Journal of Labor Economics, 20(2):201-16.

[5] Andrews, D. (1989): "Power in Econometric Applications," Econometrica, 57(5):1059-90.

[6] Banerjee, A., P. Gertler, and M. Ghatak (2002): "Empowerment and Efficiency: Tenancy Reform in West Bengal," Journal of Political Economy, 110(2):239-280.

[7] Basu, K. (1992): "Limited Liability and the Existence of Share Tenancy," Journal of Development Economics, 38(1):203-220.

[8] Bell, C. (1977): "Alternative Theories of Sharecropping: Some Tests Using Evidence from Northeast India," Journal of Development Studies, 13(July):317-46.

[9] Binswanger, H.; K. Deininger; G. Feder (1995): "Power, Distortions, Revolt and Reform in Agricultural Land Relations," in Handbook of development economics. Volume 3B, 2659-2772.

[10] Demougin, D. and C. Fluet (2001): "Monitoring versus Incentives," European Economic Review, 45:1741-64.

[11] Eswaran M., and A. Kotwal (1985): "A Theory of Contractual Structure in Agriculture," American Economic Review, v75, n3: 352-67

[12] Hallagan, W. (1978): "Self-selection by Contractual Choice and the Theory of Sharecropping'" Bell Journal of Economics,9: 344-54. 
[13] Hansen, B. (1999) "Threshold Effects in Non-Dynamic Panels: Estimation, Testing and Inference," Journal of Econometrics, 93, 345-368.

[14] Jacoby, H. and G. Mansuri (2006): "Incomplete Contracts and Holdup: Land Tenancy and Investment in Rural Pakistan," unpublished manuscript, World Bank, Washington, D.C.

[15] Johnson, D. G. (1950): "Resource Allocation Under Share Tenancy," Journal of Political Economy, Vol 58, Issue 2: 111-123.

[16] Laffont, J.-J. and D. Martimort (2001): The Theory of Incentives. Princeton University Press.

[17] Laffont, J.-J. and M. Matoussi (1995): "Moral Hazard, Financial Constraints and Sharecropping in El Oulja," Review of Economic Studies, 62(July): 381-99.

[18] Mookherjee, D. (1997): "Informational Rents and Property Rights in Land," in Property Rights, Incentives, and Welfare, edited by J. Roemer. London: Macmillan Press.

[19] Nabi, I. (1986): "Contracts, Resource Use and Productivity in Sharecropping," Journal of Development Studies, 22(2):429-42.

[20] Otsuka, K., H. Chuma, and Y. Hayami (1992) "Land and Labor Contracts in Agrarian Economies: Theories and Facts," Journal of Economic Literature, Vol. 30, No. 4, 1965-2018.

[21] Pandey, P. (2004): "Effects of Technology on Incentive Design of Share Contracts," American Economic Review, 94(4):1152-68.

[22] Shaban, R. (1987): "Testing between Competing Models of Sharecropping," Journal of Political Economy, 95(5):893-920.

[23] Shetty, S. (1988): "Limited Liability, Wealth Differences and Tenancy Contracts in Agrarian Economies," Journal of Development Economics, 29:1-22.

[24] Stiglitz, J. (1974) "Incentives and Risk Sharing in Sharecropping'" Review of Economic Studies, vol (41), No. 2, 219-255.

[25] van Garderen, K. and C. Shah (2002) "Exact Interpretation of Dummy Variables in Semilogarithmic Equations," Econometrics Journal, volume 5, 149-159. 


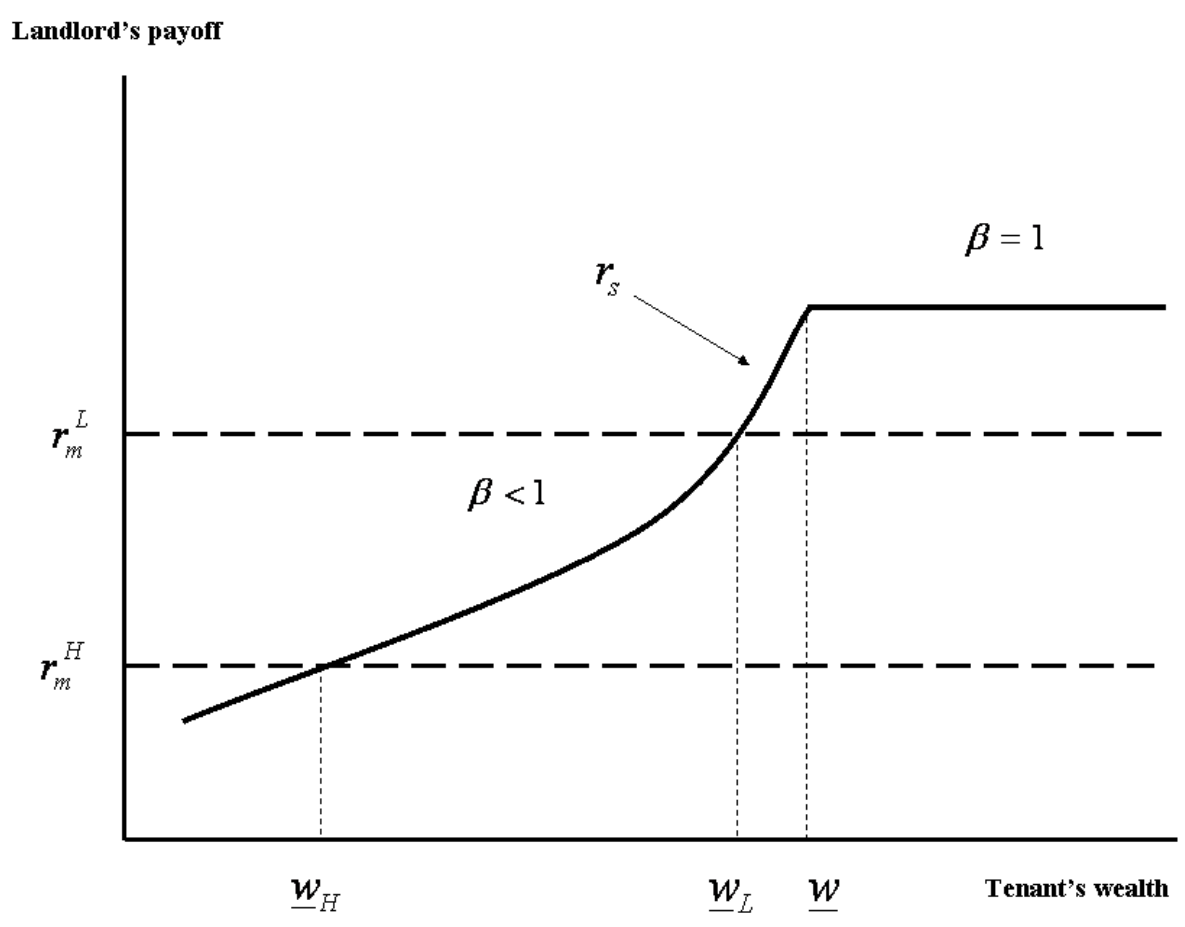

Figure 1: Supervision-Incentive tradeoff 
Table 1: Number of Plots in Estimation Samples

\begin{tabular}{lccccc}
\hline \hline & \multicolumn{4}{c}{ Major Crop Yield } & Family \\
\cline { 2 - 5 } Household type & \multicolumn{3}{c}{ household-year basis } & hh basis & Labor \\
\cline { 2 - 5 } & IFPRI-93 & PRHS-01 & Total & Total & IFPRI-93 \\
\hline OCS $^{\mathbf{a}}$ & 163 & 240 & 403 & 771 & 234 \\
& $(81)$ & $(113)$ & $(194)$ & $(348)$ & $(119)$ \\
Multi-plot & 462 & $1256^{\mathbf{c}}$ & $1718^{\mathbf{b}}$ & $1993^{\mathbf{b}}$ & $692^{\mathbf{b}}$ \\
& $(174)$ & $(351)$ & $(525)$ & $(624)$ & $(236)$ \\
All types & 719 & 2088 & $2807^{\mathbf{b}}$ & 2807 & $882^{\mathbf{b}}$ \\
& $(279)$ & $(670)$ & $(949)$ & $(949)$ & $(322)$ \\
& & & & & \\
$\begin{array}{l}\text { Multi-plot } \\
\text { sharecropper }\end{array}$ & - & $264^{\mathbf{d}}$ & - & - & - \\
\hline
\end{tabular}

Notes: Number of sharecropped plots in parentheses. The household basis groups plots of a given household together regardless of survey year; household-year basis groups plots of a given household separately by survey year. Family labor data are available only in IFPRI-93.

a Owner-cum-sharecropper, but also includes a few renter-cum-sharecroppers.

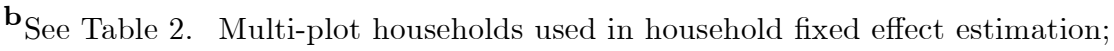

all types used in village fixed effects estimation.

$\mathbf{c}_{\text {See Table } 3 .}$

$\mathbf{d}_{\text {See Table } 4 .}$ 
Table 2: Effect of Sharecropping on Yields and Family Labor

\begin{tabular}{|c|c|c|c|c|c|}
\hline \multirow[t]{2}{*}{ Type of fixed effects: } & \multicolumn{3}{|c|}{ Household-year } & \multirow{2}{*}{$\begin{array}{c}\text { Household } \\
(4)\end{array}$} & \multirow{2}{*}{$\begin{array}{c}\frac{\text { Village }}{(5)} \\
5\end{array}$} \\
\hline & (1) & $(2)$ & (3) & & \\
\hline \multicolumn{6}{|l|}{ Normalized yield } \\
\hline$\%$ differential $(\gamma)$ & -2.7 & -2.8 & -2.3 & -2.1 & -0.0 \\
\hline Standard error & $(4.2)$ & $(4.2)$ & $(3.9)$ & $(3.9)$ & $(2.5)$ \\
\hline Controls & - & $\mathrm{A}$ & $\mathrm{A}, \mathrm{B}$ & $\mathrm{A}, \mathrm{B}$ & $\mathrm{A}, \mathrm{B}$ \\
\hline$p$-value controls & - & 0.000 & 0.000 & 0.000 & 0.000 \\
\hline \multicolumn{6}{|c|}{ Family labor in all tasks $\mathbf{a}$} \\
\hline$\%$ differential $(\gamma)$ & -18.1 & -8.7 & -6.4 & - & 5.3 \\
\hline Standard error & $(8.1)$ & $(7.0)$ & $(7.0)$ & & $(5.4)$ \\
\hline Controls & - & A & $\mathrm{A}, \mathrm{B}$ & - & $\mathrm{A}, \mathrm{B}$ \\
\hline$p$-value controls & - & 0.000 & 0.000 & & 0.000 \\
\hline \multicolumn{6}{|c|}{ Family labor in all tasks except harvesting/threshing ${ }^{\mathbf{a}}$} \\
\hline$\%$ differential $(\gamma)$ & -12.9 & -4.2 & -1.9 & - & 6.1 \\
\hline Standard error & $(9.6)$ & $(8.4)$ & $(8.3)$ & & $(6.2)$ \\
\hline Controls & - & A & $\mathrm{A}, \mathrm{B}$ & - & $\mathrm{A}, \mathrm{B}$ \\
\hline$p$-value controls & - & 0.000 & 0.000 & & 0.000 \\
\hline
\end{tabular}

Notes: See Table 1 for samples and Appendix Table A.1 for variable definitions and descriptive statistics: $\mathrm{A}=$ \{plot characteristics $\}, \mathrm{B}=\{$ crop composition $\}$. All specifications use fixed effects at household or village level as indicated. Standard error adjusted for household clustering in column (4). Village fixed effects specifications in column (5) include household random effects.

${ }^{\mathbf{a}}$ Coefficients and standard errors from logarithmic specifications are converted to percentage changes. No distinction between household and household-year fixed effects since labor data are available only in IFPRI-93. 
Table 3: Landlord Supervision and Yields

\begin{tabular}{|c|c|c|c|c|c|}
\hline & Mean (s.d.) & (1) & $(2)$ & $(3)$ & $(4)$ \\
\hline Sharecropped plot ${ }^{\mathbf{a}}$ & 0.28 & $\begin{array}{c}-4.4 \\
(4.8)\end{array}$ & $\begin{array}{c}-5.0 \\
(4.9)\end{array}$ & $\begin{array}{c}-2.5 \\
(4.9)\end{array}$ & $\begin{array}{c}-3.7 \\
(5.0)\end{array}$ \\
\hline Supervised $\left(m_{c i}>\widehat{k}\right)^{\mathbf{b}}$ & 0.65 & $\begin{array}{c}28.1 \\
(10.9)\end{array}$ & $\begin{array}{c}27.4 \\
(11.0)\end{array}$ & $\begin{array}{c}25.8 \\
(11.0)\end{array}$ & $\begin{array}{c}24.9 \\
(11.0)\end{array}$ \\
\hline \multicolumn{6}{|l|}{ Tenant characteristics $\mathbf{b}$} \\
\hline Recent $(\leq 3$ yrs. $)$ & 0.29 & - & $\begin{array}{c}-5.7 \\
(10.2)\end{array}$ & - & $\begin{array}{c}-1.8 \\
(10.3)\end{array}$ \\
\hline Relative of landlord & 0.34 & - & $\begin{array}{c}10.0 \\
(10.3)\end{array}$ & - & $\begin{array}{c}16.7 \\
(11.0)\end{array}$ \\
\hline \multicolumn{6}{|l|}{ Landlord characteristics $\mathbf{b}$} \\
\hline Log of landholdings & $\begin{array}{c}5.78 \\
(1.64)\end{array}$ & - & - & $\begin{array}{c}0.050 \\
(0.040)\end{array}$ & $\begin{array}{c}0.071 \\
(0.043)\end{array}$ \\
\hline Owns a tractor & 0.32 & - & - & $\begin{array}{c}12.7 \\
(12.4)\end{array}$ & $\begin{array}{c}10.4 \\
(12.5)\end{array}$ \\
\hline Owns a tubewell & 0.21 & - & - & $\begin{array}{c}13.6 \\
(14.8)\end{array}$ & $\begin{array}{c}13.1 \\
(14.8)\end{array}$ \\
\hline \multicolumn{6}{|l|}{ p-value controls: } \\
\hline Plot characteristics & & 0.000 & 0.000 & 0.000 & 0.000 \\
\hline Crop composition & & 0.000 & 0.000 & 0.000 & 0.000 \\
\hline
\end{tabular}

Notes: Standard errors in parentheses. Dependent variable is major crop yield scaled by average yield on unsupervised sharecropped plots $\times 100$. All regressions include household fixed effects. $\mathrm{N}=1256$ plots (see Table 1 ).

${ }^{\mathbf{a}}$ Coefficient renormalized to represent percentage change relative to owner-cultivation.

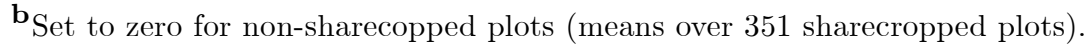


Table 4: Landlord Supervision and Yields among Multi-plot Sharecroppers

\begin{tabular}{|c|c|c|c|c|c|}
\hline & Mean (s.d.) & $(1)$ & $(2)$ & $(3)$ & $(4)$ \\
\hline Supervised $\left(m_{c i}>\widehat{k}\right)$ & 0.66 & $\begin{array}{c}73.1 \\
(22.4)\end{array}$ & $\begin{array}{c}78.1 \\
(22.9)\end{array}$ & $\begin{array}{c}69.4 \\
(23.2)\end{array}$ & $\begin{array}{c}74.1 \\
(23.8)\end{array}$ \\
\hline \multicolumn{6}{|l|}{ Tenant characteristics } \\
\hline Recent $(\leq 3$ yrs. $)$ & 0.26 & - & $\begin{array}{c}19.5 \\
(18.3)\end{array}$ & - & $\begin{array}{c}21.0 \\
(18.6)\end{array}$ \\
\hline Relative of landlord & 0.30 & - & $\begin{array}{l}12.3 \\
(19.7)\end{array}$ & - & $\begin{array}{l}16.8 \\
(20.7)\end{array}$ \\
\hline \multicolumn{6}{|l|}{ Landlord characteristics } \\
\hline Log of landholdings & $\begin{array}{c}5.87 \\
(1.71)\end{array}$ & - & - & $\begin{array}{c}0.038 \\
(0.081)\end{array}$ & $\begin{array}{c}0.067 \\
(0.085)\end{array}$ \\
\hline Owns a tractor & 0.35 & - & - & $\begin{array}{c}6.4 \\
(20.1)\end{array}$ & $\begin{array}{c}2.9 \\
(20.3)\end{array}$ \\
\hline Owns a tubewell & 0.22 & - & - & $\begin{array}{c}6.4 \\
(31.6)\end{array}$ & $\begin{array}{c}7.5 \\
(31.7)\end{array}$ \\
\hline \multicolumn{6}{|l|}{ p-value controls: } \\
\hline Plot characteristics & & 0.157 & 0.116 & 0.200 & 0.136 \\
\hline Crop composition & & 0.000 & 0.000 & 0.000 & 0.000 \\
\hline
\end{tabular}


Table 5: Generalized Ordered Logit Model of Contract Choice

\begin{tabular}{|c|c|c|c|c|c|}
\hline & \multirow{2}{*}{$\begin{array}{r}\text { Mean } \\
\text { (s.d.) }\end{array}$} & (1) & \multicolumn{3}{|c|}{$\overline{(2)}$} \\
\hline & & $\mathbf{S}-\mathbf{M S}^{\mathbf{a}}$ & $\mathbf{F R}-\mathbf{S}^{\mathbf{b}}$ & $\mathbf{S}-\mathbf{M S}^{\mathbf{a}}$ & $\mathbf{F R}-\mathbf{S}^{\mathbf{b}}$ \\
\hline Plot outside landlord's village & 0.14 & $\begin{array}{c}-1.59 \\
(0.367)\end{array}$ & $\begin{array}{l}-0.766 \\
(0.382)\end{array}$ & $\begin{array}{c}-1.73 \\
(0.427)\end{array}$ & $\begin{array}{c}-0.727 \\
(0.389)\end{array}$ \\
\hline $\begin{array}{l}H_{0}: d_{i}=0 \quad \text { vs. } \\
H_{1}: d_{i}<0 \quad i=1,2\end{array}$ & & {$[0.000]$} & {$[0.022]$} & {$[0.000]$} & {$[0.031]$} \\
\hline \multicolumn{6}{|l|}{ Landlord characteristics } \\
\hline Log of landholdings & $\begin{array}{c}3.96 \\
(1.43)\end{array}$ & - & - & $\begin{array}{c}0.648 \\
(0.242) \\
{[0.007]}\end{array}$ & $\begin{array}{c}0.192 \\
(0.165) \\
{[0.246]}\end{array}$ \\
\hline Owns a tractor & 0.11 & - & - & $\begin{array}{l}-1.33 \\
(0.593) \\
{[0.024]}\end{array}$ & $\begin{array}{c}0.511 \\
(0.567) \\
{[0.367]}\end{array}$ \\
\hline Owns a tubewell & 0.10 & - & - & $\begin{array}{c}1.10 \\
(0.519) \\
{[0.033]}\end{array}$ & $\begin{array}{l}-0.656 \\
(0.505) \\
{[0.194]}\end{array}$ \\
\hline$H_{0}: d_{1}=d_{2} \quad$ vs. $H_{1}: d_{1}<d_{2}$ & & & & & \\
\hline Other plot characteristics: $\chi_{(8)}^{2}$ & & {$[0.042]$} & {$[0.014]$} & {$[0.103]$} & {$[0.049]$} \\
\hline
\end{tabular}

Note: Standard errors, adjusted for village-level clustering, in parentheses; p-values (onesided for the relevant structural hypotheses tests) in square brackets. Each equation includes all plot characteristics listed in Appendix, dummies for seasonal leases, and province dummies. Sample size is 609 landlord-owned plots.

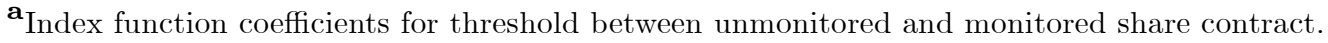

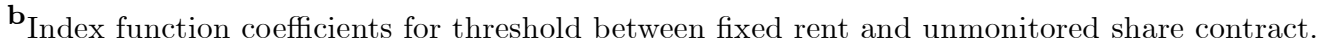




\section{Appendix}

Table A.1: Descriptive Statistics

\begin{tabular}{|c|c|c|c|c|}
\hline & \multicolumn{2}{|c|}{ 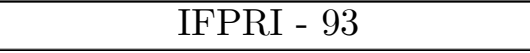 } & \multicolumn{2}{|c|}{ PRHS - 01} \\
\hline & Owned/Rented & Sharecropped & Owned/Rented & Sharecropped \\
\hline Plot area $(\text { acres })^{\mathbf{a}}$ & $\begin{array}{c}10.8 \\
(15.4)\end{array}$ & $\begin{array}{c}9.9 \\
(8.9)\end{array}$ & $\begin{array}{c}8.3 \\
(14.1)\end{array}$ & $\begin{array}{c}7.4 \\
(8.2)\end{array}$ \\
\hline $\log ($ plot value/acre $)$ & $\begin{array}{l}10.6 \\
(1.1)\end{array}$ & $\begin{array}{l}10.3 \\
(1.1)\end{array}$ & $\begin{array}{c}9.5 \\
(1.0)\end{array}$ & $\begin{array}{c}9.1 \\
(1.0)\end{array}$ \\
\hline Plot outside village & 0.07 & 0.06 & 0.07 & 0.11 \\
\hline $\begin{array}{l}\text { Year-round canal } \\
\text { irrigation }\end{array}$ & 0.43 & 0.58 & 0.31 & 0.53 \\
\hline $\begin{array}{l}\text { Seasonal canal } \\
\text { irrigation }\end{array}$ & 0.09 & 0.10 & 0.23 & 0.21 \\
\hline Tubewell access & 0.18 & 0.10 & 0.57 & 0.46 \\
\hline Sandy soil & 0.11 & 0.19 & 0.18 & 0.24 \\
\hline Maira soil & 0.24 & 0.24 & 0.29 & 0.20 \\
\hline Chikni soil & 0.03 & 0.03 & 0.24 & 0.36 \\
\hline Cotton $\mathbf{b}$ & 0.02 & 0.00 & 0.13 & 0.09 \\
\hline Rice $^{\mathbf{b}}$ & 0.19 & 0.38 & 0.15 & 0.30 \\
\hline Sugarcane $^{\mathbf{b}}$ & 0.11 & 0.12 & 0.07 & 0.12 \\
\hline Maize $^{\mathbf{b}}$ & 0.08 & 0.05 & 0.08 & 0.06 \\
\hline Normalized yield $^{\mathbf{c}}$ & $\begin{array}{l}1.00 \\
(0.75)\end{array}$ & $\begin{array}{c}0.98 \\
(0.66)\end{array}$ & $\begin{array}{c}1.00 \\
(0.71)\end{array}$ & $\begin{array}{c}1.02 \\
(0.66)\end{array}$ \\
\hline$N$ & 440 & 279 & 1418 & 670 \\
\hline 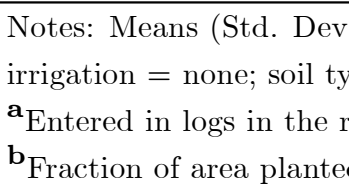 & $\begin{array}{l}\text { for village fixed eff } \\
\text { e = clay. } \\
\text { gressions. } \\
\text { to five major crops }\end{array}$ & cts sample $(2807$ & Omitted cate & ories: canal \\
\hline
\end{tabular}

